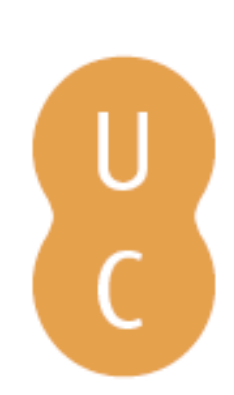

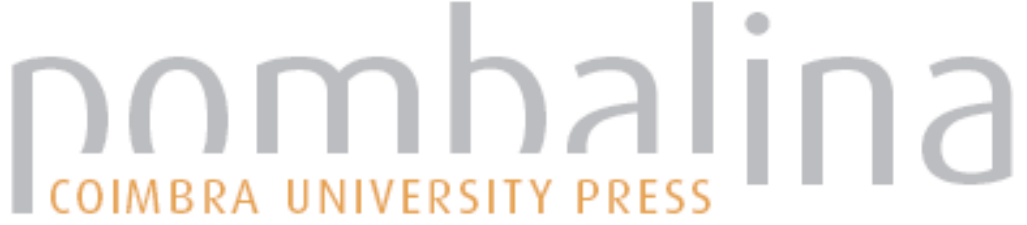

\section{Motivos olímpicos nos Epinícios de Baquílides}

Autor(es): $\quad$ Pinheiro, Joaquim J. S.

Publicado por: Imprensa da Universidade de Coimbra

URL

persistente:

URI:http://hdl.handle.net/10316.2/38369

DOI:

DOI:http://dx.doi.org/10.14195/978-989-26-0371-1_7

Accessed : $\quad$ 26-Apr-2023 14:36:10

A navegação consulta e descarregamento dos títulos inseridos nas Bibliotecas Digitais UC Digitalis, UC Pombalina e UC Impactum, pressupõem a aceitação plena e sem reservas dos Termos e Condições de Uso destas Bibliotecas Digitais, disponíveis em https://digitalis.uc.pt/pt-pt/termos.

Conforme exposto nos referidos Termos e Condições de Uso, o descarregamento de títulos de acesso restrito requer uma licença válida de autorização devendo o utilizador aceder ao(s) documento(s) a partir de um endereço de IP da instituição detentora da supramencionada licença.

Ao utilizador é apenas permitido o descarregamento para uso pessoal, pelo que o emprego do(s) título(s) descarregado(s) para outro fim, designadamente comercial, carece de autorização do respetivo autor ou editor da obra.

Na medida em que todas as obras da UC Digitalis se encontram protegidas pelo Código do Direito de Autor e Direitos Conexos e demais legislação aplicável, toda a cópia, parcial ou total, deste documento, nos casos em que é legalmente admitida, deverá conter ou fazer-se acompanhar por este aviso.

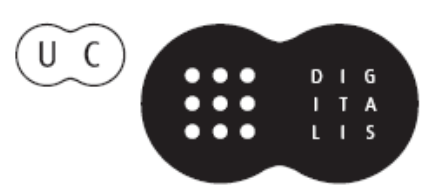


FRANCISCO DE OLIVEIRA

Coordenação

Ospírito Olímpico

no

novo milénio 


\section{MOTIVOS OLÍMPICOS NOS EPINÍCIOS DE BAQUÍLIDES}

Jo aquim J. S. Pinheiro

Universidade da Madeira

A criação literária grega não foi indiferente ao espírito agónico evidenciado nos eventos desportivos. Durante os séculos VI e V a. C., a par de alguns fragmentos de Simónides de Céos, provavelmente o mais antigo cultor das odes epiníciasO, outros dois poetas contemporâneos se evidenciaram: Pindaro e Baquílidesí ${ }^{2}$ ). É precisamente a partir dos epinícios 3, 9 e I3<3) do poeta de Céos, Baquílides ( 510 a. C.), que procuraremos realçar alguns motivos relacionados com a actividade desportiva.

Tendo em conta o estado fragmentário dos epinícios citados, algumas informações são puramente conjecturais. Além disso, desiludase aquele que procurar nos epinícios motivos concretos sobre a competição, como o estado psicológico dos atletas antes da prova, a caracterização dos diversos competidores, as condições atmosféricas, as reacções do público ou outros momentos próprios de um evento desportivo. No entanto, juntamente com a arqueologia, a fonte literária ajuda-nos a perceber o valor do atleta e dos festivais atléticos na sociedade grega.

0) Para outros, Arquíloco é o mais antigo.

(2) O recente estudo de Valérie VISA-ONDARÇUHU, L'Image de l'Athlète d'Homère à la fin du Ve siècle avant J.-C, Paris, Les Belles Lettres, 1999, oferece no Cap. II «Gloire et Louange éternelles aux Athlètes Victorieux», p. 73-181, uma leitura actualizada e interessante dos versos que celebram a vitória dos atletas.

(3) O texto grego utilizado é da edição da Loeb: Creek Lyric IV. Bacchylides, Corinna, and Others, edited and translated by David A. CAMPBELL, Harvard University Press, 1992. 
Antes, porém, aclare-se o significado de epinícioí4), género da poesia lírica coral, cuja evolução desde as origens é muito discutida. Da leitura das odes de Simónides, Baquílides e Pindaro, percebemos que se trata de uma composição poética com o objectivo de celebrar os vencedores dos grandes agones atléticos da Grécia: os Jogos Olímpicos, os Jogos Píticos, os Jogos Istmicos e os Jogos Nemeus, respectivamente consagrados a Zeus, Apoio, Poséidon e Zeus. Estes quatro eventos panhelénicos eram os mais competitivos, formando um periodos. Ao atleta que vencesse a mesma modalidade nos quatro jogos chamava-se periodonikes.

Observando ainda a obra dos três poetas, notamos a repetição de traços fundamentais, como o louvor do vencedor, da sua pátria ou família, o mito e a introdução de mensagens de cariz gnómico. Seja por razões de ordem social, como o facto de a aristocracia privilegiar os feitos atléticos, seja por ter sido um meio de propaganda política, a verdade é que o epinicio granjeou notoriedade, visível pela sua definição autónoma como forma literária. O epinicio era cantado e dançado por um coro, com o acompanhamento de um instrumento musical, sendo a sua representação feita no próprio lugar da vitória ou no regresso apoteótico do vencedor à sua pátria. Quanto aos seus elementos convencionais, esperamos extraí-los da análise dos epinícios 3, 9 e 13 do poeta de Céos, cuja obra foi incluída no cânone alexandrino dos nove grandes líricos.

O critério que presidiu à escolha deste epinícios e não de outros baseou-se na intenção de expor três vencedores em modalidades distintas. Assim, o epinicio 3 louva o triunfo de Hierão de Siracusa na corrida de cavalos, nos Jogos Olímpicos; por sua vez, o epinicio 9 é dedicado à vitória obtida por Automedonte de Fliunte no pentatlo, por ocasião dos Jogos Nemeus; o epinicio 13, por fim, celebra o vencedor 96 do pancrácio, Píteas de Egina, nos Jogos Nemeus.

Comecemos pelo epinicio 3(5). Deixaremos de lado as causas que levaram Hierão de Siracusa a encarregar Baquílides de compor a ode,

(4) Para a definição de epinicio, propomos Anne P. BURNETT, The Art of Bacchylides, Harvard University Press, 1985, p. 48-60.

(s) Uma análise deste e dos epinícios 9 e 13 é feita por Anne P. BURNETT, op. cit, Caps. 5, 6 e 7 . 
para celebrar o seu maior triunfo, pelo facto de ter ganho a prova mais importante do mais prestigiado evento, a corrida de cavalos dos Jogos Olímpicos, em 468 a. C. Também não nos ocuparemos de saber se em algum momento da ode o povo é que profere as palavras em vez do poeta. Cinjamo-nos, apenas, aos motivos que estruturam a ode.

$\mathrm{Na}$ invocação inicial à Musa Clio ( $ү \lambda u \kappa u ́ \delta \omega \rho \varepsilon ~ K \lambda \varepsilon o l$, Clio de doces

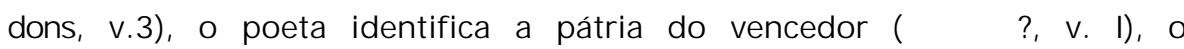

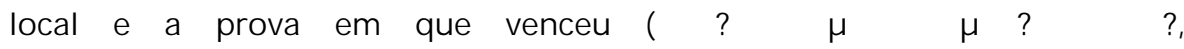
velozes cavalos que correram em Olímpia, v.3-4) e o nome do vencedor ('lepwvo?, v. 4). A vitória de Hierão é explicada pela acção de três

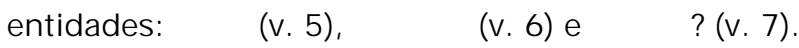

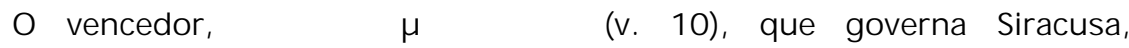
tem como característica essencial da sua acção política o facto de não ocultar o ouro (v. 13-14). Se nos versos 15 e 16 a vitória de Hierão é festejada em Siracusa, logo transitamos para o santuário délfico, sublinhando-se a glorificação que o deus Apoio merece, fruto da sua generosidade. Tanto a alusão à riqueza (ploutos, v. 13) como a referência apolínea preparam um elemento central no epinicio (v.22-62): o mito de Creso(6).

$\mathrm{Na}$ personalidade de Creso, figura que remetia na época para a riqueza, realça-se a sua eusebeia (v.6l) e generosidade para com Apoio, por isso o deus o salvou das chamas devoradoras da pira.

Como o provam os versos 63 a 71, o mito de Creso tem a função de iluminar analogias com o vencedor. Assim como Creso é generoso, também Hierão é o que dá mais ouro a Apoio, em toda a Hélade. Neste epinicio, a sequência de palavras relacionadas com a abundância ou

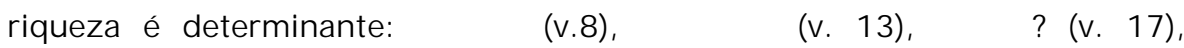

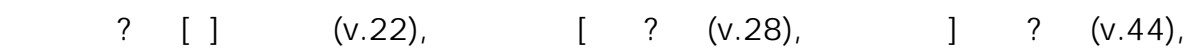

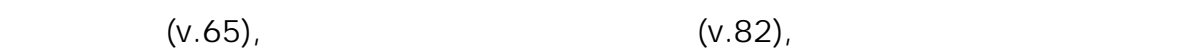

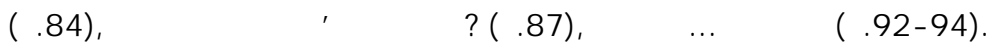

(6) Cf. Heródoto I, 85-6. Sobre este tema vide J. PÉRON, “Les Mythe de Crésus et de Méléagre dans les Odes III et V de Bacchylide”, REC 91 (1978), p. 307-339. Para a tradução dos versos do mito de Creso vide M. H. ROCHA PEREIRA, Hélade. Antologia da Cultura Grega, Coimbra, $1990^{5}$, p. 181 - 2. 
Quanto à caracterização de Hierão, ele é philippos (v.69), areios (v.69), possuidor do skaptron de Zeus (v.70) e, como alguns interpretam o verso 71, impulsionador da arte das Musas, isto pelas condições que proporcionou ao desenvolvimento cultural.

Depois do enkomion feito ao vencedor, o poeta introduz uma secção (v.72- 92) de cariz gnómico, cujas ideias fortes são:

1. o reconhecimento da efemeridade (ephameros, v.73) da condição humana;

2. acentua-se a diferença entre a areta (v.90) e o soma (v.9l), pois enquanto o envelhecimento do corpo é inevitável, o brilho da virtude não diminui.

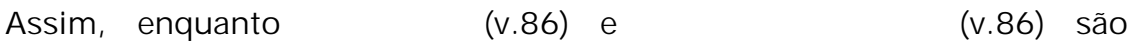
athanatoi, o homem é mortal, sendo o canto poético uma forma de perpetuar os kosmoi da condição humana. Esta é a função do epinicio do

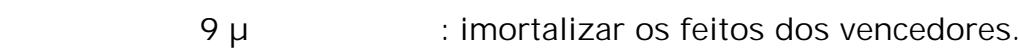

No epinicio 9, o poeta autodefme-se como o Moúoav ye

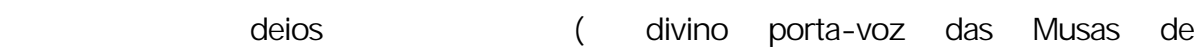
violáceos olhos, v.4) ao invocar as Xápixes (v. I). O objectivo do logos poético é bem definido: celebrar Fliunte (v.4), cidade dória do Peloponeso, e Zeus Nemeu (v.4-5). Antes de nomear o vencedor, conta a conhecida luta de Héraclès com o Leão de Némea, um dos seus trabalhos, mito fundador dos Jogos Nemeus (v. 10-24), que ocorriam de dois em dois anos tal como os Jogos Istmicos.

Depois de retardado o anúncio do nome do vencedor, apesar de Fliunte constituir um indício da sua pátria, eis que finalmente surge $\left(^{7}\right) \circ$

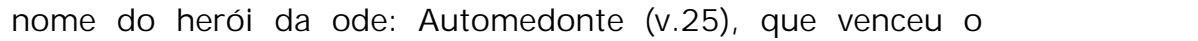
(v.27). Pelas informações que temos, o pentatlo na Antiguidade, reflectido a educação dos jovens gregos e, em Esparta, também das jovens, era composto pelas seguintes provas: a corrida, salto em comprimento (sem corrida), lançamento do dardo, lançamento do disco e luta. Ora, destas cinco provas Automedonte venceu três: o díokov

(7) Uso de prophetes como o arauto que anuncia o nome do vencedor (Cf. George A. KENNEDY (ed.), The Cambridge History of Ljterary Criticism, Vol. I Classical Criticism, C. U. P., 1997r, p. 27). 


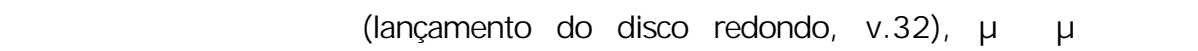

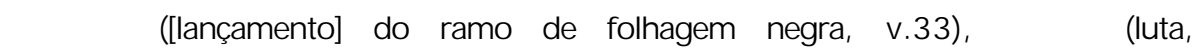
v.36). Depois da segunda vitória, o poeta atesta 0 efeito que 0

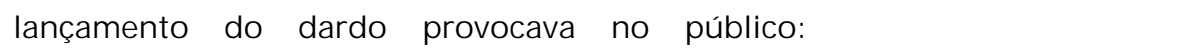
(impulsionava o clamor da multidão, v.35). Este feito de Automedonte

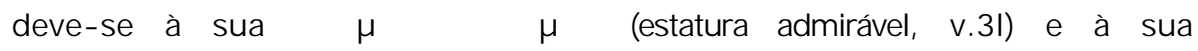

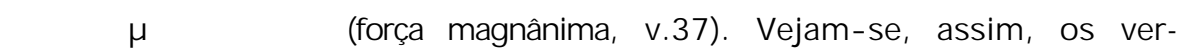
sos 27 a 39 :

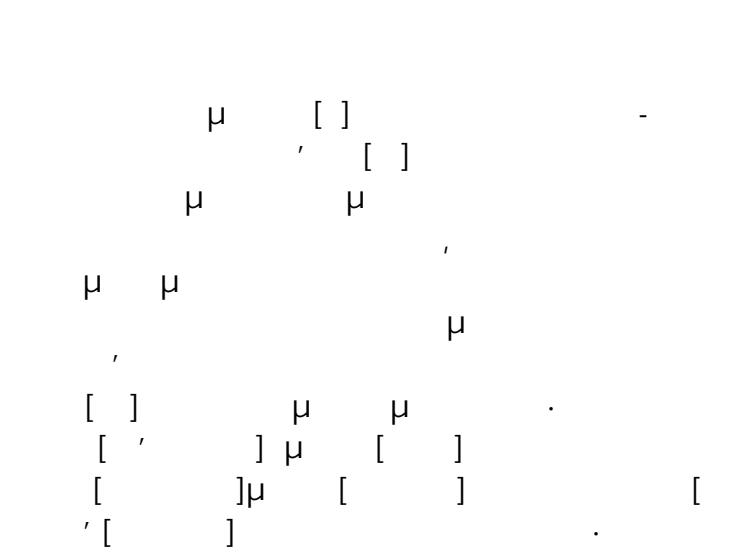

De facto, distinguia-se entre os pentatletas

como brilham a luz dos astros e

a lua resplandecente da noite que divide o mes.

Atravessando o imenso círculo dos Helenos,

ele mostrava a sua estatura admirável

no lançamento do disco redondo,

e no enviar da mão para o elevado éter

um ramo de salgueiro, de folhagem negra,

que impulsionava o clamor da multidão,

ou depois de terminar o frémito da luta.

Aproximando da terra, com uma força magnânima,

os corpos de membros vigorosos,

veio ao Asopo de purpúreos redemoinhos.

Até ao fim do epinicio, faz-se o louvor dos descendentes de Fliunte, alude-se à celebração da vitória de Automedonte e, tal como no epinicio 3, repete-se a capacidade que o poema tem de imortalizar a nika. Nos últimos três verso ficamos a conhecer o nome do pai do 
vencedor, Timóxeno, além de se exortar à celebração da vitória no

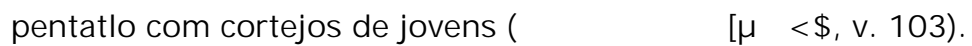

O epinicio $13\left(^{8}\right)$, certamente a mais extensa e mais homérica $\left(^{9}\right)$ composição do rouxinol de Céos, além de repetir a invocação feita à musa Clio no epinicio 3, volta a referir o mito etiológico da fundação dos Jogos Nemeus, ou seja, a luta que opôs Héraclès ao Leão de Némea, sugerindo, claramente, que se trata de um topos deste tipo de composição coral. Mais à frente, no verso 58, distingue-se a figura de Zeus, como deus tutelar dos Jogos Nemeus.

Entre os versos 67 e 76 temos a primeira secção dedicada ao louvor do vencedor, afirmando-se que é filho de Lâmpon e que no regresso à cidade de Éaco(10), Egina, recebeu muitos louvores pela sua vitória no pancrácio (v.75-76), prova que combinava a luta e o pugilato, sendo, normalmente, a última dos Jogos. A propósito das regras desta prova, sabemos que era necessário obrigar o oponente a admitir a derrota, quando em perigo de estrangulação ou fractura de um membro. Para o conseguir apenas era proibido morder ou arrancar olhos.

Como é habitual nos epinícios, o poeta faz o louvor da pátria do vencedor, preparando a passagem para o mito central. Tal como em Pindaro, narram-se os feitos dos descendentes de Eaco e de Endeis, Peleu e Télamon, e dos filhos destes, respectivamente, Aquiles e Ájax, os principais baluartes da vitória dos aqueus sobre os troianos. Na parte final da narração mitológica, ainda que o texto esteja muito mutilado, percebemos que a inevitável morte silenciou o ressoar dos dardos, mas os feitos gloriosos jamais serão esquecidos. Com efeito, a cidade de Éaco distingue-se pela tima (v. 183), eunomia (v. 186), eusebeia (v. 188), condição sine qua non para a eirene (v. 189).

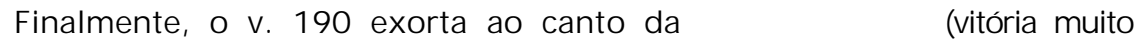
100 gloriosa) de Píteas e de MenandroO '), seu treinador, pelos cuidados

(8) Cf. Nemeia $V$ de Pindaro, com o mesmo tema.

(9)Cf. P. E. EASTERLING- B. M. W. KNOX, The Cambridge of Classica! Literature, vol. I, Part I, C.U.P., 1990, p. 196- 7.

(10) Filho de Zeus e da ninfa Egina, filha de Asopo.

0 ') Cf. Pindaro, Nemeia V, 48. 
dispensados. A necessidade de um treinador indica, claramente, que o atleta era sujeito a uma preparação antes da competição, para dar expressão às suas capacidades.

Louvada a glória do vencedor, segue-se uma parte gnómica com diversos preceitos dos quais evidenciamos: "o que não domina a inveja de ousada palavra, louve o homem sábio com justiça" (v. 199-202) e "a verdade ama a vitória" (v.204- 5).

Nos últimos versos, 220 a 225, Baquílides oferece a ode como retribuição pela hospitalidade de Lâmpon. Não pense ele que é um pequeno presente porque as suas palavras desencadearão junto do povo muito apreço pelo seu filho Píteas.

Após esta breve análise, compete-nos retirar algumas ilações. Em primeiro lugar, qualquer um destes epinícios procura associar o vencedor à sua pátria, à prova em que competiu e aos Jogos, ignorandose por completo a referência dos derrotados, pois apenas interessa glorificar aquele que obteve a vitória.

Outro aspecto prende-se com as consequências da vitória. Se, por um lado, para a pátria é motivo de prestígio e de orgulho, e por isso o vencedor passa a ser heroizado, para o vencedor, por outro lado, receber o stephanos, emblema da vitória, significa atingir um momento memorável da sua biografia, sinónimo da dedicação, força e destreza, que fazem dele um modelo para qualquer cidadão. Assim, a nika atinge não só o autor de tão grande feito como contagia toda a pátria, levandoa a festejar entusiasticamente o seu regresso.

Para cumprir o programa da celebração da vitória, do vencedor e da pátria, o poeta introduz, como vimos, o mito não apenas com uma finalidade estética, mas com valor funcional, pois ele configura valores e reproduz a religiosidade da sociedade pan-helénica, irradiando dynamis e poder.

Assegurando a pervivência do kleos e do kydos, a composição coral, privada hoje do canto, da música e da dança, aplaude a vitória e a celebração, valorizando, paralelamente, princípios, como comprovam as partes de tom moralista. Na verdade, o atleta dos epinícios de Baquílides alia à sua compleição física a excelência de carácter, que é uma lição para o fenómeno desportivo da actualidade. Aliás, o próprio Comité Olímpico Intencional (COI) está consciente da necessidade de huma- 
nizar o movimento olímpico, como afirma o presidente do COI, Juan- Antonio Samaranch:

“L'Olympisme est une philosophie de la vie qui exalte et combine en un ensemble équilibré les qualités du corps, de la volonté et de l'esprit. Alliant le sport à la culture et à l'éducation, l'Olympisme s'efforce de créer un style de vie fondé sur la joie dans l'effort, la valeur éducative du bon exemple et respect des principes éthiques fondamentaux universels. Le but de l'Olympisme est de mettre le sport uni à l'art et à la culture au service du développement harmonieux de l'homme, en vue d'encourager l'établissement d'une société pacifique, soucieuse de préserver la dignité humaine."(12) 